\title{
GOLPH3 expression promotes the resistance of HT29 cells to 5-fluorouracil by activating multiple signaling pathways
}

\author{
MING-ZHEN WANG ${ }^{1}$, CHENG-ZHI QIU ${ }^{1}$, WAI-SHI YU ${ }^{1}$, YAN-TA GUO ${ }^{2}$, \\ CHUN-XIAO WANG ${ }^{1}$ and ZHI-XIONG $\mathrm{CHEN}^{1}$ \\ Departments of ${ }^{1}$ General Surgery and ${ }^{2}$ Gastroenterology, \\ The Second Affiliated Hospital of Fujian Medical University, Quanzhou, Fujian 362000, P.R. China
}

Received November 24, 2016; Accepted September 14, 2017

DOI: $10.3892 / \mathrm{mmr} .2017 .7877$

\begin{abstract}
The novel proto-oncogene Golgi phosphoprotein (GOLPH)3 is overexpressed in a variety of tumor tissues and is associated with poor prognosis. The authors previously demonstrated that GOLPH3 gene is overexpressed in colorectal cancer tissues and promotes the proliferation of colonic cancer cells by activating the phosphatidylinositol-3-kinase/protein kinase B/the mammalian target of rapamycin and Wnt/ $\beta$-catenin signaling pathways. However, to the best of the authors' knowledge, if and how the GOLPH3 gene is involved in inducing resistance to colonic cancer chemotherapy has not been reported. In the present study, the association between the overexpression of the GOLPH3 gene and resistance of HT29 colonic cancer cells to 5-fluorouracil (5-FU) was investigated. Following confirmation of the effective silencing of the GOLPH3 gene, proliferation and apoptosis of colonic cancer cells were detected by MTT assay, colony formation assay and flow cytometry, and then the mechanism of GOLPH3-induced resistance to 5-FU chemotherapy in colonic cancer cells was investigated by western blotting. The results demonstrated that the expression of phosphorylated (p)-glycoprotein and GOLPH3 was increased in HT29 cells following treatment with 5-FU, which resulted in the development of drug resistance. Silencing GOLPH3 increased the sensitivity of HT29 cells to 5-FU, reduced their tumorigenicity and partly reversed their resistance to 5-FU. The expression of p-extracellular signal-regulated kinase (pERK)1/2 and $\beta$-catenin was decreased, which indicated that its mechanism was associated with the activation of the mitogen-activated protein kinase/ERK and Wnt/ $\beta$-catenin signaling pathways.
\end{abstract}

Correspondence to: Dr Cheng-Zhi Qiu, Department of General Surgery, The Second Affiliated Hospital of Fujian Medical University, 34 Zhongshan North Road, Quanzhou, Fujian 362000, P.R. China

E-mail: qchengzhi@sohu.com

Key words: colonic cancer cells, Golgi phosphoprotein 3, Wnt signaling pathway, extracellular signal-regulated kinase $1 / 2$ signaling pathway, 5-fluorouracil, chemoresistance
Therefore, GOLPH3 may be a potential, novel target for reversing chemotherapy resistance in colon cancer.

\section{Introduction}

Colonic cancer is a common type of gastrointestinal cancer, with stage II patients exhibiting risk factors and stage III/IV patients requiring systemic chemotherapy. At present, the FOLFOX regimen, folinic acid + oxaliplatin + 5-fluorouracil (5-FU) (1-3), remains the first-line chemotherapy for colonic cancer. However, $\sim 90 \%$ of patients with malignant tumors succumb as a result of gradually decreasing sensitivity to chemotherapeutic drugs or resistance resulting from continuous use; leading to ineffective treatment $(4,5)$. Therefore, to prolong the survival time of patients with colonic cancer, it is important to study the mechanism of drug resistance and develop an effective treatment method to increase drug sensitivity.

Golgi phosphoprotein 3 (GOLPH3), also known as GPP34, is localized on human chromosome $5 \mathrm{p} 13$ and encodes an $\sim 34 \mathrm{kDa}$ protein of the Golgi complex. Numerous studies, domestic and foreign, have confirmed that GOLPH3 is a proto-oncogene (6-9). The authors previously demonstrated that GOLPH3 gene is overexpressed in colorectal cancer tissues and promotes the proliferation of colonic cancer cells by activating the phosphatidylinositol-3-kinase/protein kinase $\mathrm{B} /$ mammalian target of rapamycin and $\mathrm{Wnt} / \beta$-catenin signaling pathways. GOLPH3 overexpression can be used as an important indicator to aid assessing the prognosis of patients with colorectal cancer (10-14). However, if and how GOLPH3 gene is involved in inducing resistance to chemotherapy in colonic cancer has not been reported to date.

According to a previous study on the GOLPH3 gene and colorectal cancer (10-14), it is hypothesized that the high expression of GOLPH3 may affect resistance of colonic cancer cells to 5-FU chemotherapy. In the present study, the effect of GOLPH3 gene on chemotherapeutic drug resistance of human colonic cancer cells by small interfering (si)RNA and other techniques in vitro was investigated.

\section{Materials and methods}

Cell lines and culture. The human colorectal cancer cell line HT29 was purchased from the Type Culture Collection of 
the Chinese Academy of Sciences (Shanghai, China). Cells were maintained in RPMI-1640 medium (Invitrogen; Thermo Fisher Scientific, Inc., Waltham, MA, USA) supplemented with $10 \%$ fetal bovine serum (Sigma-Aldrich; Merck KGaA, Darmstadt, Germany) and grown in a humidified incubator with $5 \% \mathrm{CO}_{2}$ at $37^{\circ} \mathrm{C}$.

Cell groupings. The cells were divided into five groups: A control group (HT29 cells); a transfection group (HT29 cells transfected with siRNA-GOLPH3 (GCUUGCUUAAUC ATGGTTAT, Shanghai GenePharma Co., Ltd, Shanghai, China) using the liposome method, according to the manufacturer's protocol, for $50 \mathrm{nM}$ siRNA transfection of HT29 cells for $48 \mathrm{~h}$ (15); experimental group 1 (HT29 cells treated with 5-FU); experimental group 2 (transfected HT29 cells treated with 5-FU); and experimental group 3 [HT29 cells treated with the 5-FU and $50 \mu \mathrm{M}$ extracellular signal-regulated kinase (ERK)1/2 inhibitor MPD98059 (Cell Signaling Technology, Inc., Danvers, MA, USA)]. Each experimental group was maintained in culture medium containing $30 \mu \mathrm{M}$ 5-FU (Qilu Pharmaceutical Co., Ltd., Shandong, China) for $24 \mathrm{~h}$.

RNA extraction and reverse transcription-quantitative polymerase chain reaction $(R T-q P C R)$. The expression of GOLPH3 mRNA in the control and siRNA transfection groups was detected. Total RNA was extracted from cultured cells using the TRIzol ${ }^{\circledR}$ reagent (Invitrogen; Thermo Fisher Scientific, Inc.). A total of $2 \mu \mathrm{M}$ of total RNA from each sample was reverse transcribed into cDNA using the SuperScript ${ }^{\mathrm{TM}}$ III Reverse Transcriptase kit (Invitrogen; Thermo Fisher Scientific, Inc.). qPCR was performed using the SYBR Ex Taq kit (Takara Bio, Inc., Otsu Japan) and the ABI 9700 qRT-PCR detection system (Applied Biosystems; Thermo Fisher Scientific, Inc.). The qPCR conditions were an initial cycle of $20 \mathrm{sec}$ at $95^{\circ} \mathrm{C}$; followed by 45 cycles of denaturation for $10 \mathrm{sec}$ at $95^{\circ} \mathrm{C}$, annealing for $20 \mathrm{sec}$ at $60^{\circ} \mathrm{C}$ and extension for $20 \mathrm{sec}$ at $72^{\circ} \mathrm{C}$. All PCR primers were synthesized by Zimmer AG (Shanghai, China). The primers sequences were as follows: GOLPH3 forward, 5'-AGGGCGACTCCAAGGAAA-3' and reverse, 5'-TGATGTGTAACCCTCGCG-3'; and GAPDH forward, 5'-GGTCATAAGCTTGCGTTGATTAAG-3' and reverse, 5'-CTACGGAAACCTTGTTACGACTTT-3'. Taking GAPDH as an internal reference, the relative expression level was calculated using the $2^{-\Delta \Delta \mathrm{Cq}}$ equation (16).

Cell proliferation (MTT) assay. A cell suspension was seeded into a 96 -well plate, with $10^{3}$ cells/well and maintained for 24 h by the anchorage-dependent method. A total of four double-wells and four control wells, which contained cells without any other treatment, were set up in each group. Following $48 \mathrm{~h}$ culture, $10 \mu \mathrm{l} 5 \mathrm{mg} / \mathrm{ml}$ MTT reagent (Sigma-Aldrich; Merck $\mathrm{KGaA}$ ) was added to each well, followed by further culture for $4 \mathrm{~h}$ and then the culture medium was discarded. A total of $150 \mu \mathrm{l}$ dimethylsulphoxide (Sigma-Aldrich; Merck KGaA) was added to each well and the plate was agitated in the dark. Optical density at $490 \mathrm{~nm}\left(\mathrm{OD}_{490}\right)$ was measured with a microplate reader (Nanjing Huadong Electronics Group Co., Ltd, Nanjing, China). The above procedure was repeated three times. The formula used: Rate of growth inhibition in cancer cells $=\left(1\right.$-average $\mathrm{OD}_{490}$ in treatment groups/average $\mathrm{OD}_{490}$ in control groups) x100.

Colony formation assay. Cells in the logarithmic growth phase were seeded into six-well plates (500 cells/well) containing complete culture medium. The medium was changed every 3 days over the next 3 weeks. Once the clones became visible, their culture was terminated and cells were washed with PBS and fixed in $100 \%$ methanol at $37^{\circ} \mathrm{C}$ for $20 \mathrm{~min}$. Following staining with crystal violet dye for at $37^{\circ} \mathrm{C} 30 \mathrm{~min}$, cells were washed three times with PBS and clones ( $\geq 50$ cells) were counted under an inverted microscope. The above steps were repeated three times and the average cell count was calculated.

Apoptotic assay. The culture medium was centrifuged at $1,000 \mathrm{x}$ for $5 \mathrm{~min}$ at room temperature, the supernatant was discarded and the cells were resuspended in PBS. A total of 5-10 million resuspended cells were centrifuged at 1,000 x g for $5 \mathrm{~min}$ at room temperature and the supernatant was discarded. Cells were resuspended in a mixture containing $195 \mu \mathrm{l}$ Annexin binding buffer, $5 \mu \mathrm{l}$ Pacific Blue Annexin V (both, Beckman Coulter, Inc., Brea, CA, USA) and $10 \mu 1$ propidium iodide (Sigma-Aldrich; Merck KGaA) solution for 10-20 min at room temperature, and then placed in an ice bath and detected by flow cytometry (CXP software, version 2.2; FC500 flow cytometer; Beckman Coulter, Inc.).

Western blotting. Each cell line in the logarithmic growth phase was washed with PBS. The cells were lyzed in radioimmunoprecipitation assay lysis buffer [containing $50 \mathrm{mM}$ Tris-HCl, (pH 7.4), $150 \mathrm{Mm} \mathrm{NaCl}, 0.1 \%$ SDS, $1 \mathrm{mM}$ EDTA, $1 \%$ Triton X-100, $1 \mathrm{mM}$ PMSF and $1 \mathrm{mM}$ protease inhibitor cocktail] for $20 \mathrm{~min}$ on ice with occasional vortex mixing. Protein concentrations were determined using the bicinchoninic acid assay kit (Shanghai Via-gene pro bio Technologies Co., Ltd, Shanghai, China). Protein from cell lysates (30 $\mu \mathrm{g} /$ lane) were separated by $10 \%$ SDS-PAGE and transferred electrophoretically to nitrocellulose membranes (Beijing Solarbio Science and Technology Co., Ltd., Beijing, China). Membranes were blocked with 5\% skimmed milk in TBS-Tween-20 for $1 \mathrm{~h}$ at room temperature. The blots were incubated with rabbit antibodies against GOLPH3 (1:1,000; cat. no. ab 98023; Abcam, Cambridge, UK), rabbit antibodies against phosphorylated-glycoprotein (p-gp; 1:500; cat. no. ab 103477; Abcam), mouse antibodies against $\beta$-catenin (1:500; cat. no. sc-59737; Santa Cruz Biotechnology, Inc., Dallas, TX, USA), rabbit antibodies against GAPDH (1:1,000; cat. no. sc-365062; Santa), mouse antibodies against $\beta$-actin (1:1,000; cat. no. sc-47778; Santa), rabbit antibodies against ERK1/2 (1:500; cat. no. Ab 17942; Abcam) and rabbit antibodies against pERK1/2 (1:500; cat. no. ab 65142; Abcam) at $4^{\circ} \mathrm{C}$ overnight. Following washing three times with PBST for $10 \mathrm{~min}$, the membranes were incubated with horseradish peroxidase-conjugated anti-mouse and anti-rabbit immunoglobulin G (both 1:5,000; cat. nos. sc-516102 and sc-2357, respectively; Santa Cruz Biotechnology, Inc.) for $1 \mathrm{~h}$ at room temperature. The bands were visualized with Pierce enhanced chemiluminescence detection kit (cat. no. 32109, Thermo Fisher Scientific, Inc.) and the results were analyzed with Image J Software (version 1.48; National Institutes 
of Health, Bethesda, MD, USA). Relative intensity target protein $=$ target band of gray value/GAPDH (or $\beta$-actin) band gradation value. GAPDH (or $\beta$-actin) was used as a loading control.

Statistical analysis. SPSS software (version 19.0; SPSS Inc., Chicago, IL, USA) was used for data analysis and data were expressed as the mean \pm standard deviation. Dunnett's $t$ test was used to compare each experimental group with the control group. Differences among the experimental groups were compared by one-way analysis of variance. Differences between paired experimental groups were compared by Least-Significant Difference $t$ test. $\mathrm{P}<0.05$ was considered to indicate a statistically significant difference.

\section{Results}

Detection of transfection efficiency of HT29 colonic cancer cells

Expression of GOLPH3 in the HT29 human colonic cancer cell line following transfection. Compared with the control group (1.0 0.07813$)$, the relative expression of GOLPH3 mRNA in the siRNA-transfected group $(0.1468 \pm 0.0213)$ decreased significantly $(\mathrm{P}<0.01)$. A similar result was demonstrated using western blotting, which demonstrated that the GOLPH3 protein expression in HT29 cells transfected with siRNA-GOLPH3 $(0.0768 \pm 0.3992)$ was decreased compared with the control HT29 cells $(1.0033 \pm 0.2353 ; \mathrm{P}<0.01)$. siRNA transfection silenced expression of GOLPH3 (Fig. 1).

Proliferation of cancer cells in the transfection group. An MTT assay demonstrated that $\mathrm{OD}_{490}$ of the transfected group was decreased compared with the control group $(\mathrm{P}<0.01)$, which indicated that the proliferative ability of GOLPH3 was significantly decreased as a result of silencing (Fig. 2). Similar results were demonstrated in the colony-formation assay, where the colony number of tumor cells in the transfection group was significantly decreased compared with the control group $(\mathrm{P}<0.01$; Fig. 3$)$, which demonstrated that the tumorigenicity was significantly decreased following silencing GOLPH3.

Investigation of the effect exerted by GOLPH3 on the resistance of colonic cancer cells to treatment with 5-FU Effect of silencing GOLPH3 on the proliferation of HT29 cells treated with 5-FU. The MTT assay demonstrated that, in experimental groups 1 (HT29 cells treated with 5-FU; $\mathrm{P}<0.05$ ) and 2 (transfected HT29 cells treated with 5-FU; P<0.001), $\mathrm{OD}_{490}$ was significantly decreased compared with the control group. As a result of treatment with 5-FU, the $\mathrm{OD}_{490}$ of experimental group 2 was significantly decreased compared with experimental group $1(\mathrm{P}<0.001 ;$ Fig. 4). This demonstrates that knockout of GOLPH3 could increase the sensitivity of HT29 colon cancer cells to 5-FU. Similar results were demonstrated in the colony-formation assay, where the colony number of the tumor cells in the experimental group 1 and 2 was significantly decreased compared with the control group. Treatment with 5-FU resulted in the colony number in experimental group 2 being significantly decreased compared with experimental group $1(\mathrm{P}<0.001$; Fig. 5$)$. These results demonstrated that
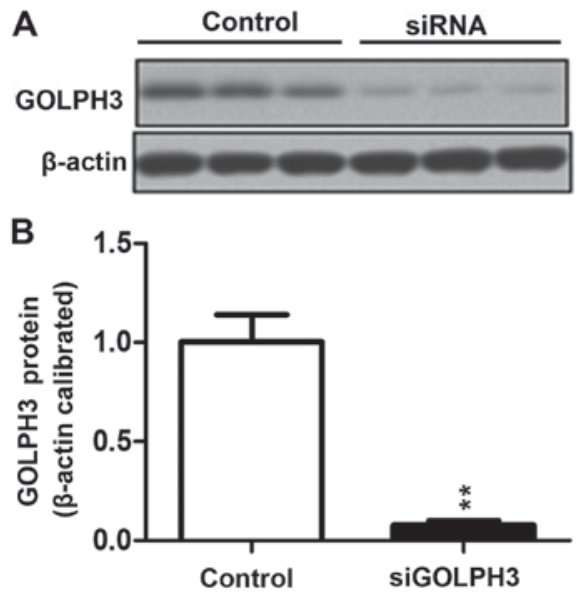

C

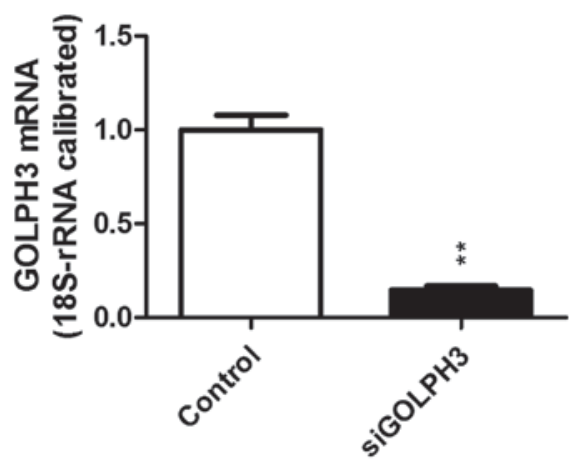

Figure 1. Data analysis of the level of GOLPH3 protein and mRNA in the control and transfection groups. (A) Western blotting of GOLPH3 expression in HT29 cells. (B) Quantitative analysis of western blotting. (C) Quantitative analysis of GOLPH3 mRNA. Representative images of three individual experiments and $\beta$-actin was used as the loading control. Values are expressed as percentage of untreated control. ${ }^{* *} \mathrm{P}<0.01$ vs. control group. GOLPH3, Golgi phosphoprotein; si, small interfering.

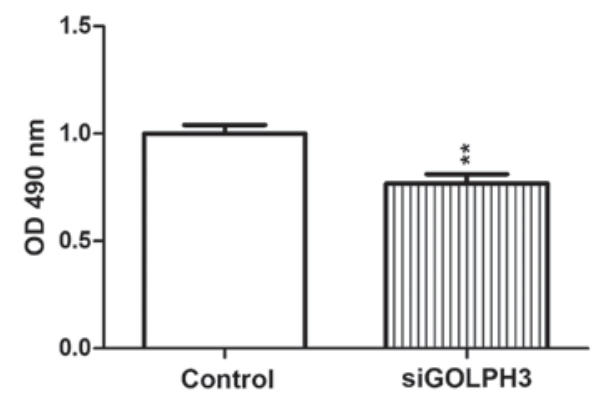

Figure 2. Analysis of the inhibition of HT29 colonic cancer cell proliferation in the control and transfection groups. Cell growth inhibition rate was calculated by measuring the absorbance at $490 \mathrm{~nm}$. The growth inhibition rates in the siGOLPH3 group was $23.1 \%$. Values are expressed as percentage of untreated control. ${ }^{* *} \mathrm{P}<0.01$ vs. control. siGOLPH3, small interfering Golgi phosphoprotein 3 RNA; OD, optical density.

knockout of GOLPH3 decreased the colony-forming ability of HT29 colon cancer cells following treatment with 5-FU.

Effect of silencing GOLPH3 on apoptosis in HT29 cells following treatment with 5-FU. The percentage of apoptotic cancer cells in the experimental groups was significantly increased in group $1(\mathrm{P}<0.01)$ and group 2 $(\mathrm{P}<0.001)$ compared with that in the control group (Fig. 6). 

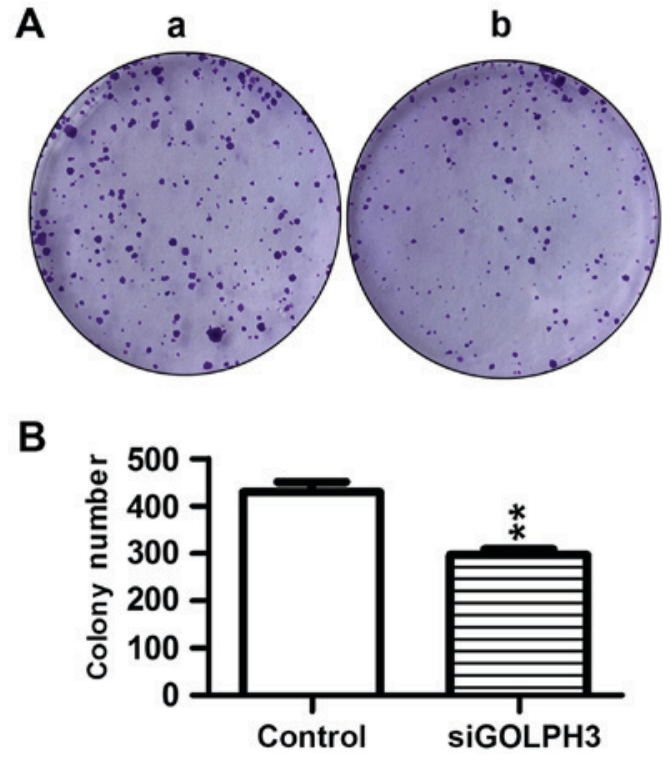

Figure 3. Investigation of the colony number of the control and transfected group of HT29 cells. (A) Colonies of HT29 colonic cancer cells in the, (A-a) control and (A-b) transfection group (siGOLPH3 RNA). (B) Quantitative comparison of the number of HT29 colonic cancer cells in each group. ${ }^{* *} \mathrm{P}<0.01$ vs. control. siGOLPH3, small interfering Golgi phosphoprotein 3.

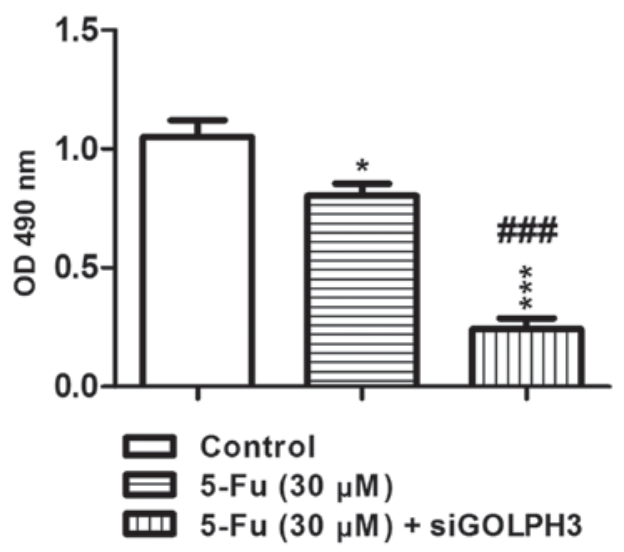

Figure 4. Inhibition of HT29 colonic cancer cell proliferation in experimental groups 1 (5-FU) and 2 (5-FU+siGOLPH3 RNA). Cell growth inhibition rate was calculated by measuring the absorbance at $490 \mathrm{~nm}$. The growth inhibition rates of experimental groups 1 and 2 were 19.6 and $75.8 \%$, respectively. Values are expressed as percentage of the untreated control, ${ }^{*} \mathrm{P}<0.05$, ${ }^{* * * *} \mathrm{P}<0.001$ vs. control; ${ }^{\# \# \#} \mathrm{P}<0.001$ vs. 5-FU $(30 \mu \mathrm{M}) .5-\mathrm{FU}, 5$ fluorouracil; GOLPH3, Golgi phosphoprotein 3; si, small interfering; OD, optical density.

The percentage of apoptotic cells in experimental group 2 was significantly increased compared with experimental group $1(\mathrm{P}<0.001$; Fig. 6). These results demonstrated that knockdown of GOLPH3 increased the percentage of apoptotic HT29 colon cancer cells following treatment with 5-FU.

Investigation of the mechanism by which GOLPH3 affects the resistance of colonic cancer cells to 5-FU chemotherapy by western blotting. Difference in the expression of GOLPH3, p-gp, ERK1/2, $\beta$-catenin and pERK1/2 protein in HT29 colonic cancer cells in each group were detected using western blotting and the mechanism by which HT29 cells develop
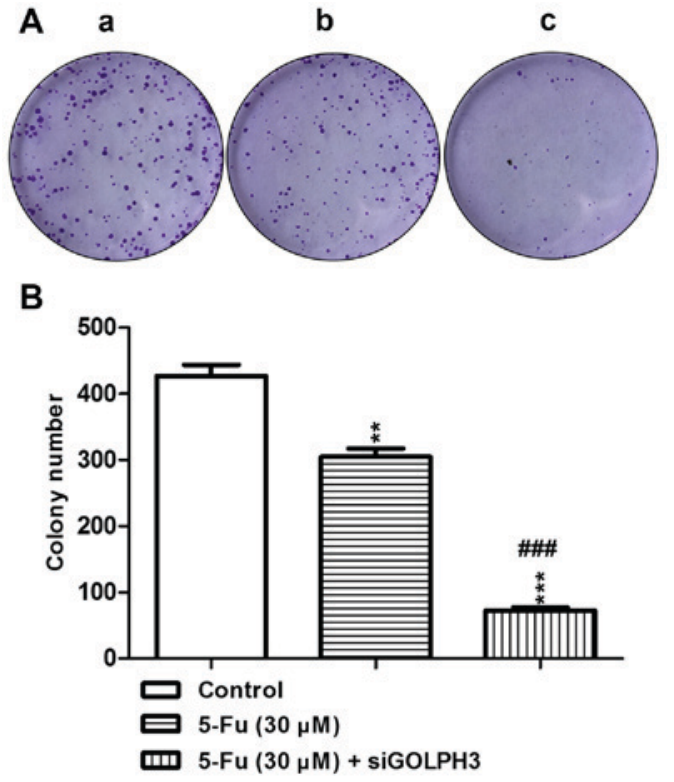

Figure 5. Analysis of the formation of cell colonies by HT29 colonic cancer cells. (A) Colonies of HT29 colonic cancer cells in experimental groups 1 and 2. (A-a) control, (A-b) experimental groups 1 (5-FU) and (A-c) experimental groups 2 (5-FU+si GOLPH3 RNA). (B) Comparison of the number of HT29 colonic cancer cell colonies in each group. ${ }^{* *} \mathrm{P}<0.01,{ }^{* * * *} \mathrm{P}<0.001$ vs. control; ${ }^{\# \#} \mathrm{P}<0.001$ vs. 5-FU (30 $\left.\mu \mathrm{M}\right)$. 5-FU, 5 fluorouracil; GOLPH3, Golgi phosphoprotein 3 ; si, small interfering.
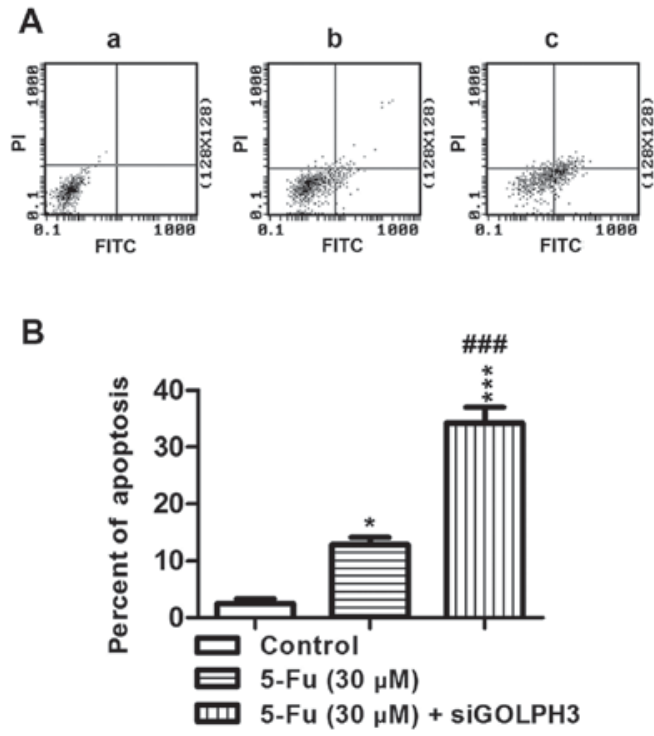

Figure 6. Analysis of the level of apoptosis in colonic cancer cells. (A) Flow cytometric data of HT29 colonic cancer cells detected by Annexin-FITC/PI double staining method. (A-a) control, (A-b) experimental groups 1 (5-FU) and (A-c) experimental groups 2 (5-FU+siGOLPH3). (B) Comparison of the percentage of apoptotic of HT29 colonic cancer cells between groups. ${ }^{*} \mathrm{P}<0.05,{ }^{* * *} \mathrm{P}<0.001$ vs. control; ${ }^{\# \# \#} \mathrm{P}<0.001$ vs. 5-FU $(30 \mu \mathrm{M}) .5-\mathrm{FU}, 5$ fluorouracil; GOLPH3, Golgi phosphoprotein 3; si, small interfering; FITC, fluorescein isothiocyanate; PI, propidium iodide.

GOLPH3-induced resistance to 5-FU chemotherapy was investigated.

Compared with the control group, there was significant increase in expression of p-gp in the cells treated with 5-FU in group 1 ( $\mathrm{P}<0.01$; Fig. 7 ; Table I), which implied that resistance was induced in colonic cancer cells treated with $5-\mathrm{FU}$, and 
Table I. Relative expression of proteins in experimental groups 1 and 2.

\begin{tabular}{lccc}
\hline Protein & Control & Experimental group 1 & Experimental group 2 \\
\hline GOLPH3 & $0.9667 \pm 0.09356$ & $3.6335 \pm 0.5739^{\mathrm{a}}$ & $0.5201 \pm 0.17598^{\mathrm{b}, \mathrm{c}}$ \\
p-ERK1/2 & $1.0002 \pm 0.33347$ & $2.6614 \pm 0.43782^{\mathrm{d}}$ & $0.2391 \pm 0.08942^{\mathrm{b}, \mathrm{c}}$ \\
$\beta$-catenin & $1.0003 \pm 0.10137$ & $2.3235 \pm 0.41784^{\mathrm{d}}$ & $0.9330 \pm 0.04897^{\mathrm{e}}$ \\
p-gp & $1.0005 \pm 0.19883$ & $2.4239 \pm 0.26066^{\mathrm{d}}$ & $0.4662 \pm 0.15896^{\mathrm{b}, \mathrm{c}}$ \\
\hline
\end{tabular}

Data are presented as the mean \pm standard deviation and expressed as percentage of the untreated control. Experimental group 1,5-FU; experimental group $2,5-\mathrm{FU}+\mathrm{siGOLPH} .{ }^{\mathrm{a}} \mathrm{P}<0.001$, ${ }^{\mathrm{b}} \mathrm{P}<0.05$ vs. control; ${ }^{\mathrm{C}} \mathrm{P}<0.001$ vs. group 1 ; ${ }^{\mathrm{d}} \mathrm{P}<0.01$ vs. control; ${ }^{\mathrm{e}} \mathrm{P}<0.01$ vs. group 1 . GOLPH3, Golgi phosphoprotein 3; p-ERK, phosphorylated extracellular signal-regulated kinase; p-gp, phosphorylated glycoprotein; si, small interfering.

expression of GOLPH3, pERK1/2 and $\beta$-catenin proteins also significantly increased (all $\mathrm{P}<0.01$ vs. control; Fig. 7). The results of the present study suggested that the expression of GOLPH3 and the signaling pathways of mitogen-activated protein kinase (MAPK)/ERK and $\mathrm{Wnt} / \beta$-catenin were involved in the mechanism of resistance to 5-FU.

Compared with the control group and experimental group 1, when the HT29 cells with GOLPH3 stably silenced were treated with 5-FU, the expression of GOLPH3 and p-gp was significantly decreased in experimental group $2(\mathrm{P}<0.05$; Fig. 7; Table I), which implied that silencing GOLPH3 would decrease the resistance of HT29 colonic cancer cells to 5-FU to a certain extent and that the GOLPH3 gene is involved in the resistance of colonic cancer cells to 5-FU.

The results also demonstrated that there was no marked difference in the expression of ERK1/2 between all the groups; however, the expression of pERK1/2 in experimental group 2 was significantly decreased compared with experimental group 1, which demonstrated that silencing the GOLPH3 gene could reduce the activation of the MAPK/ERK signaling pathway by reducing the production of pERK1/2. The level of $\beta$-catenin protein expression in group 2 was significantly decreased compared with group 1 , which implied that silencing the GOLPH3 gene by treatment with 5-FU could decrease its expression and inhibit activation of the Wnt/ $\beta$-catenin signaling pathway. Therefore, GOLPH3 could affect the resistance of HT29 cells to 5-FU by activating the MAPK/ERK and Wnt/ $\beta$-catenin signaling pathway.

Further experiments demonstrated that the expression of $\beta$-catenin and $\mathrm{p}$-gp in experiment group 3 , which was treated with an MAPK/ERK signaling pathway inhibitor, was significantly decreased compared with the control group and experimental group 1 (Fig. 8; Table II). This result demonstrated that inhibiting the MAPK/ERK signaling pathway would partly reverse resistance of HT29 colonic cancer cells to 5 -FU, which confirmed the hypothesis suggested by the results of experimental group 2.

\section{Discussion}

5-FU is a pyrimidine that inhibits thymidylate synthetase (17). Metabolic activation results in 5-FU being incorporated into RNA, which interferes with RNA function and prevents DNA synthesis. This restricts the proliferation of cancer cells and ultimately leads to their death. There are several
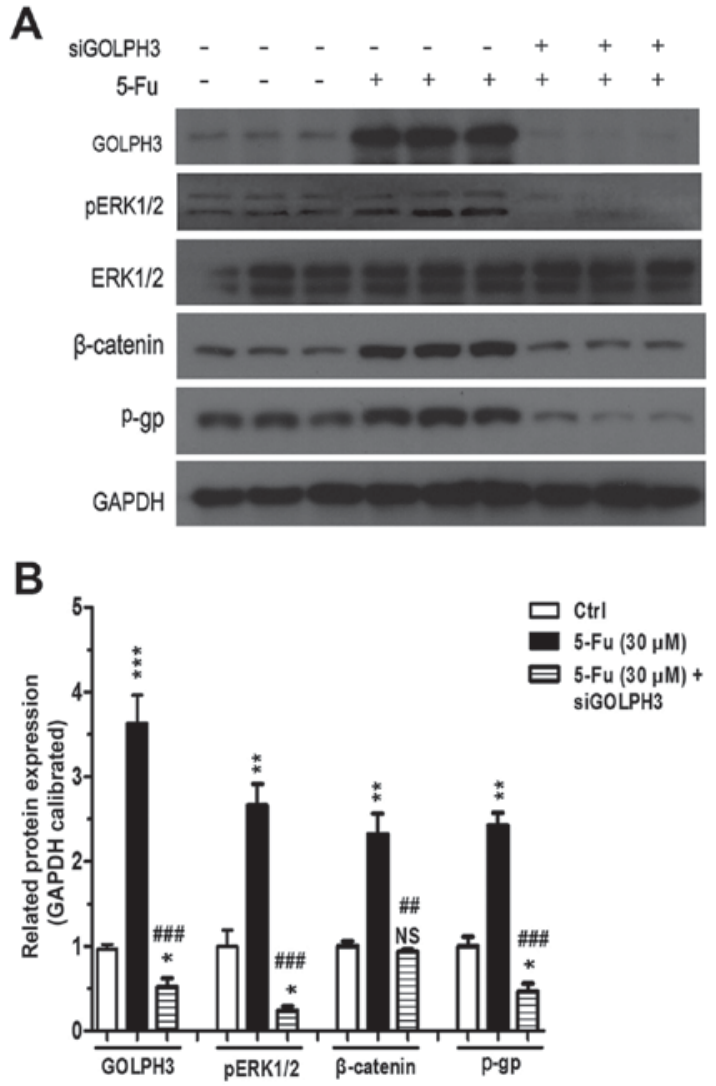

Figure 7. Expression of proteins in experimental groups 1 (5-FU) and 2 (5-FU+small interferring-GOLPH3). Representative images of three individual experiments, GAPDH was the loading control. (A) Western blotting protein band images. (B) Quantitative analysis of western blotting. Values are expressed as percentage of untreated Ctrl. ${ }^{*} \mathrm{P}<0.05,{ }^{* *} \mathrm{P}<0.01,{ }^{* * *} \mathrm{P}<0.001$ vs. Ctrl; ${ }^{\# \#} \mathrm{P}<0.01,{ }^{\# \#} \mathrm{P}<0.001$ vs. 5-FU $(30 \mu \mathrm{M})$. NS, not significant; 5-FU, 5 fluorouracil; GOLPH3, Golgi phosphoprotein 3; pERK1/2, phosphorylated extracellular signal-regulated kinase; $\mathrm{p}$-gp, phosphorylated glycoprotein; Ctrl, control.

mechanisms for 5-FU resistance, including drug metabolic pathway abnormalities, abnormal gene expression and signaling pathway abnormalities $(18,19)$. The mechanisms of abnormal gene expression and signaling pathway activation has become a popular area in current study on the resistance of colonic cancer to chemotherapy. The novel proto-oncogene GOLPH3 is overexpressed in a variety of tumor tissues and is associated with poor prognosis, which has attracted much attention. 
Table II. Relative expression of proteins in experimental groups 1 and 3.

\begin{tabular}{lccc}
\hline & Control & Experimental group 1 & Experimental group 3 \\
\hline$\beta$-catenin & $1.0000 \pm 0.1870$ & $1.9372 \pm 0.2133^{\mathrm{b}}$ & $0.6375 \pm 0.02795^{\mathrm{a}, \mathrm{d}}$ \\
p-gp & $1.0000 \pm 0.2796$ & $1.5134 \pm 0.1428^{\mathrm{a}}$ & $0.5678 \pm 0.1275^{\mathrm{a}, \mathrm{c}}$ \\
\hline
\end{tabular}

Data are presented as the mean \pm standard deviation and expressed as percentage of untreated control. ${ }^{\mathrm{a}} \mathrm{P}<0.05$, ${ }^{\mathrm{b}} \mathrm{P}<0.001 \mathrm{vs}$. Control; ${ }^{\mathrm{c}} \mathrm{P}<0.01$, ${ }^{\mathrm{d}} \mathrm{P}<0.001$ vs. 5-FU $(30 \mu \mathrm{M})$. Experimental group 1, 5-FU; experimental group 3, 5-FU+PD98059; p-gp, phosphorylated glycoprotein; 5-FU, 5 fluorouracil.

A

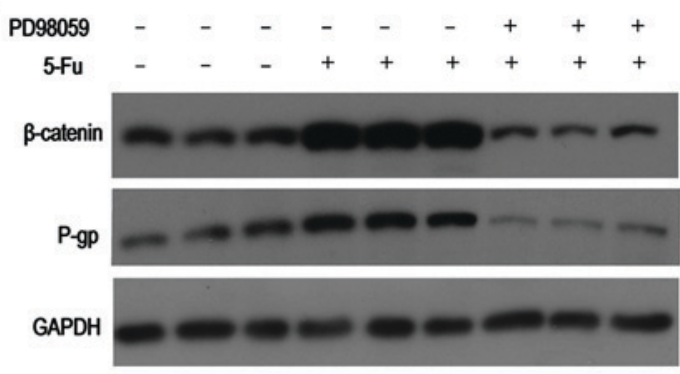

B

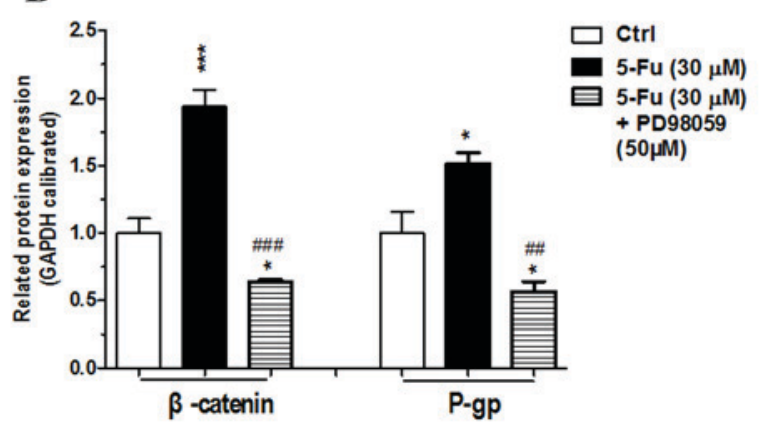

Figure 8. Expression of proteins in experimental groups 1 (5-FU) and 3 (5-FU+PD98059). (A) Western blotting protein band images. (B) Quantitative analysis of western blotting. Representative images of three individual experiments, GAPDH was used as the loading control. Values are expressed as percentage of untreated control, ${ }^{*} \mathrm{P}<0.05,{ }^{* * *} \mathrm{P}<0.001$ vs. $\mathrm{C} t r 1 ;{ }^{\# \#} \mathrm{P}<0.01$, ${ }^{\# \# \#} \mathrm{P}<0.001$ vs. 5 -FU $(30 \mu \mathrm{M})$. p-gp, phosphorylated glycoprotein; Ctrl, control; 5-FU, 5 fluorouracil; GOLPH3, Golgi phosphoprotein 3.

Expression of p-gp and GOLPH3 was increased in HT29 cells following treatment with 5-FU, which caused the development of drug resistance. Silencing GOLPH3 expression increased the sensitivity of HT29 cells to 5-FU, reduced their tumorigenicity and partly reversed their resistance to 5-FU. The expression of pERK $1 / 2$ and $\beta$-catenin was decreased, which indicated that the mechanism of resistance was associated with the activation of the MAPK/ERK and Wnt/ $\beta$-catenin signaling pathways.

It has been demonstrated that the MAPK/ERK and Wnt/ $\beta$-catenin signaling pathways are involved in drug resistance in a number of types of cancer including breast cancer $(20,21)$. The authors previously demonstrated that GOLPH3 could activate the Wnt/ $\beta$-catenin signaling pathway to promote the proliferation of colonic cancer cells (14), which was confirmed in the present study. In addition, it was demonstrated that GOLPH3 may activate the MAPK/ERK signaling pathway in colonic cancer.

It was also demonstrated that $\beta$-catenin expression was significantly decreased following inhibition of the MAPK/ERK signaling pathway, which confirmed that there is an association between the Wnt/ $\beta$-catenin and MAPK/ERK signaling pathways in the mechanism of 5-FU resistance in colonic cancer. Jeon et al (22) demonstrated that in hepatic progenitor cells the Wnt/ $\beta$-catenin and MAPK/ERK signaling pathways worked together to promote or suppress tumors developing with Wnt3 alpha, adenomatous polyposis coli protein and Ras (23). Kim et al (24) hypothesize that there is a hidden cancer-promoting, positive feedback cycle between the two pathways, which is important for cancer formation. This suggests that inhibiting certain molecules in the feedback cycle could be used as a target for cancer therapy.

An important mechanism in 5-FU cytotoxicity in colonic cancer cells is DNA damage $(17,25)$. Novel studies have demonstrated that DNA damage can act on the DNA-pyruvate kinase (PK)-GOLPH3-unconventional myosin-XVIIIa (MYO18a) signaling pathway, which increases the cell survival rate. This pathway links the DNA damage response directly to the Golgi apparatus. If any components of the pathway are removed the ability of drugs that induce DNA damage to kill cancer cells could be enhanced, by inhibiting cell proliferation and increasing apoptosis $(26,27)$. It is hypothesized that the involvement of GOLPH3 in the resistance of HT29 cells to 5-FU may be a result of DNA damage and activation of the DNA-PK-GOLPH3-MYO18A pathway, which prevents HT29 colonic cancer cells from being killed by 5 -FU.

In conclusion, GOLPH3 expression could be involved in the resistance of HT29 colonic cancer cells to 5-FU. The mechanism of resistance may be that activation of the Wnt/ $\beta$-catenin and MAPK/ERK signaling pathways promote resistance to 5-FU. Silencing expression of GOLPH3 partly reverses drug resistance. GOLPH3 may be a potential novel target for reversing drug resistance in colonic cancer.

\section{Acknowledgements}

The present study was supported by the Natural Science Foundation of Fujian Province, China (grant no. 2015J01438). 


\section{References}

1. Cunningham D, Atkin W, Lenz HJ, Lynch HT, Minsky B, Nordlinger B and Starling N: Colorectal cancer. Lancet 375: $1030-1047,2010$

2. Loree JM and Cheung WY: Optimizing adjuvant therapy and survivorship care of stage III colon cancer. Future Oncol 12: 2021-2035, 2016

3. Rogowski W and Sulżyc-Bielicka V: Optimal duration of a first-line palliative chemotherapy in disseminated colorectal cancer-a review of the literature from a developing country perspective. Contemp Oncol (Pozn) 20: 210-214, 2016.

4. Hu T, Li Z, Gao CY and Cho CH: Mechanisms of drug resistance in colon cancer and its therapeutic strategies. World J Gastroenterol 22: 6876-6889, 2016.

5. Tan S, Shi H, Ba M, Lin S, Tang H, Zeng X and Zhang X: miR-409-3p sensitizes colon cancer cells to oxaliplatin by inhibiting Beclin-1-mediated autophagy. Int J Mol Med 37: 1030-1038, 2016.

6. Scott KL, Kabbarah O, Liang MC, Ivanova E, Anagnostou V, Wu J, Dhakal S, Wu M, Chen S, Feinberg T, et al: GOLPH3 modulates mTOR signalling and rapamycin sensitivity in cancer. Nature 459: 1085-1090, 2009.

7. Scott KL and Chin L: Signaling from the Golgi: Mechanisms and models for Golgi phosphoprotein 3-mediated oncogenesis. Clin Cancer Res 16: 2229-2234, 2010.

8. Zeng Z, Lin H, Zhao X, Liu G, Wang X, Xu R, Chen K, Li J and Song L: Overexpression of GOLPH3 promotes proliferation and tumorigenicity in breast cancer via suppression of the FOXO1 transcription factor. Clin Cancer Res 18: 4059-4069, 2012.

9. Kunigou O, Nagao H, Kawabata N, Ishidou Y, Nagano S, Maeda S, Komiya S and Setoguchi T: Role of Golph3 and Golph3L in the proliferation of human rhabdomyosarcoma. Oncol Rep 26: 1337-1342, 2011.

10. Qiu CZ, Yu WS and Wang CX: Expression and clinical significance of Golgi phosphorylation protein 3 in colorectal cancer tissues. Chin J Exp Surg 30: 461-463, 2013 (In Chinese).

11. Yu WS, Qiu CZ and Wang CX: Golph3 expression and apoptosis in colorectal cancer cells. Clin Oncol 40: 1094-1463, 2013 (In Chinese).

12. Yang XF, Qiu CZ and Wang CX: Relationship between golgi phosphorylation protein 3 expression and prognosis in colorectal cancer. Chin J General Surg 23: 1362-1366, 2014 (In Chinese).

13. Guo YT, Qiu CZ, Huang ZX, Yu WS, Yang XF and Wang MZ: Correlational research of Golgi phosphorylation protein 3 expression in colorectal cancer. World J Gastroenterol 21: 13473-13479, 2015.

14. Qiu CZ, Wang MZ, Yu WS, Guo YT, Wang CX and Yang XF: Correlation of GOLPH3 gene with wnt signaling pathway in human colon cancer cells. J Cancer 7: 928-934, 2016.
15. Ah KK, Young KJ, Ah LY, Min A, Yil BY and Heon SM: Entamoeba histolytica induces cell death of HT29 colonic epithelial cells via NOX1-Derived ROS. Korean J Parasitol 51:61-68, 2013.

16. Livak KJ and Schmittgen TD: Analysis of relative gene expression data using real-time quantitative PCR and the 2(-Delta Delta $\mathrm{C}(\mathrm{T})$ ) method. Methods 25: 402-408, 2001

17. Wigmore PM, Mustafa S, El-Beltagy M, Lyons L, Umka J and Bennett G: Effects of 5-fu. Adv Exp Med Biol 678: 157-164, 2010.

18. Zhang N, Yin Y, Xu SJ and Chen WS: 5-fluorouracil: Mechanisms of resistance and reversal strategies. Molecules 13: 1551-1569, 2008.

19. Zhang X, Shi H, Tang H, Fang Z, Wang J and Cui S: miR-218 inhibits the invasion and migration of colon cancer cells by targeting the PI3K/Akt/mTOR signaling pathway. Int J Mol Med 35: 1301-1308, 2015.

20. Zhang Y, Moerkens M, Ramaiahgari S, de Bont H, Price L, Meerman J and van de Water B: Elevated insulin-like growth factor 1 receptor signaling induces antiestrogen resistance through the MAPK/ERK and PI3K/Akt signaling routes. Breast Cancer Res 13: R52, 2011.

21. Zhang H, Zhang X, Wu X, Li W, Su P, Cheng H, Xiang L, Gao P and Zhou G: linterference of frizzled 1 (FZD1) reverses multidrug resistance in breast cancer cells through the Wnt/ $\beta$-catenin pathway. Cancer Lett 323: 106-113, 2012.

22. Jeon SH, Yoon JY, Park YN, Jeong WJ, Kim S, Jho EH, Surh YJ and Choi KY: Axin inhibits extracellular signal-regulated kinase pathway by ras degradation via beta-catenin. J Biol Chem 28: 14482-14492, 2007.

23. Jin C, Samuelson L, Cui CB, Sun Y and Gerber DA: MAPK/ERK and Wnt/ $\beta$-Catenin pathways are synergistically involved in proliferation of Sca-1 positive hepatic progenitor cells. Biochem Biophys Res Commun 409: 803-807, 2011.

24. Kim D, Rath O, Kolch W and Cho KH: A hidden oncogenic positive feedback loop caused by crosstalk between Wnt and ERK pathways. Oncogene 26: 4571-4579, 2007.

25. Matuo R, Sousa FG, Escargueil AE, Grivicich I, Garcia-Santos D, Chies JA, Saffi J, Larsen AK and Henriques JA: 5-Fluorouracil and its active metabolite FdUMP cause Dna damage in human SW620 colon adenocarcinoma cell line. J Appl Toxicol 29: 308-316, 2009

26. Farber-Katz SE, Dippold HC, Buschman MD, Peterman MC, Xing M, Noakes CJ, Tat J, Ng MM, Rahajeng J, Cowan DM, et al: DNA damage triggers Golgi dispersal via DNA-PK and GOLPH3. Cell 156: 413-427, 2014.

27. Buschman MD, Rahajeng J and Field SJ: GOLPH3 links the Golgi, DNA damage, and cancer. Cancer Res 75: 624-627, 2015. 